\title{
Advanced Technology for Machining Tapered Threads of Pipe Coupling
}

\author{
Rasulov Nariman Mogbil, Nadirov Ugurlu Muhammed", Abbasova Irada Aziz, \\ Mammadov Arastun Salman, Shabiyev Elgun Tagi
}

Department of Mechanical Engineering, Azerbaijan Technical University, Baku, Azerbaijan

\section{Email address:}

nariman.rasulov@yahoo.com (Rasulov N. M.),n_ugurlu@mail.ru (Nadirov U. M.), irada.abbasova.69@mail.ru (Abbasova I. A.), arastunmamedov@mail.ru (Mammadov A. S.), shebiyev@list.ru (Shabiyev E. T.)

${ }^{*}$ Corresponding author

\section{To cite this article:}

Rasulov Nariman Mogbil, Nadirov Ugurlu Muhammed, Abbasova Irada Aziz, Mammadov Arastun Salman, Shabiyev Elgun Tagi. Advanced Technology for Machining Tapered Threads of Pipe Coupling. American Journal of Engineering and Technology Management. Vol. 5, No. 2, 2020, pp. 35-40. doi: 10.11648/j.ajetm.20200502.11

Received: December 4, 2019; Accepted: December 23, 2019; Published: May 28, 2020

\begin{abstract}
Subject of research. In the oil industry, parts such as a coupling that have differently directed tapered threads are widely used. The coaxiality of these threads is an indicator of the quality of workmanship and determines the performance of threaded joints. Purpose of work. Improving the manufacturing capacity of the coupling and the accuracy of coaxiality of their differently directed tapered threads. Method. Processing of internal conic smooth and threaded surfaces is carried out in parallel from one and two ends of the coupling, with one installation and position. Implementation. The technology of processing the internal surfaces of the coupling with tapered threads on both sides is proposed, various processing schemes are proposed, a multivariate processing technology is given, the designs of some technological tools and equipment for the implementation of technological processes are proposed. The main results. Some of the proposed options were tested in production, in which all the inner surfaces of the coupling and the ends are processed from one end of the coupling, sequentially, with one installation and position, and gave good results. Practical significance. The machine time for processing conical smooth and threaded surfaces is reduced by more than 1.5 times, the accuracy of coaxiality of multidirectional conical threads is increased by about two times. Conclusion. Application of the proposed technologies, designs of elements of equipment and accessories for their implementation will increase the efficiency and manufacture and operation of parts such as couplings, including their tapered threaded joints.
\end{abstract}

Keywords: Coupling, Machining, Different-directional Tapered Threads, Accuracy, Coaxiality, Performance

\section{Introduction}

In oil production, in the oilfield equipment are widely used couplings with tapered threads. Couplings are used to connect elements of various equipment, as well as drill, tubing and casing pipes $[1,2]$.

Couplings have connecting, different directional taper threads from two ends (Figure 1, a). Tapered threaded joints must ensure tightness and be able to accept high values of axial forces and torque (Figure 1, b). Over time, drill deep wells. For this reason, the requirements for the exploitation performance of threaded joints are continuously increasing. Couplings and connecting pipes fulfill their purpose in an upright position. The masses of the pipe create axial forces in the pipe and threaded

joints. Deviation of the tapered threads of the coupling from the coaxiality is the reason for the uneven distribution of axial force along the threaded connection, as well as around the circumference $\left(\mathrm{Q}_{1}>\mathrm{Q}_{2} ;\right.$ Figure 1, b). As a result, the carrying capacity of threaded joints of pipes and couplings and their cyclic durability are decreasing [1-4].

Currently, in modern machine tools, including those used in Azerbaijan (for example, machines of the EMAQ type), the inner surfaces of the couplings are processed in two of installations (or in one installation, but in two positions of the coupling), mainly on special machine tools for are processed couplings. When machining tapered threads and internal 
surfaces of couplings in two installations (or two positions of couplings), deviations from the coaxiality of tapered threads, processed in different installations are inevitable.

The experience of the formation of various surfaces on metal-cutting machines show that when processing surfaces in different installations, the resulting errors in basing give rise to errors in the relative positions of the machined surfaces [5-8]. In addition, when processing tapered threads and surfaces of movement of the cutting tool relative to the workpiece is realized along two coordinate axes. Thus, the accuracy of the parameters of tapered threads and surfaces depends on the accuracy of movement of the tool in two directions. As you know, the accuracy of the closing dimension of the dimensional chain (in this case, formed during processing of sizes) depends on the number of components [9-13]. Therefore, the reduction in the number of movements during the formation of surfaces, i.e. reducing the number of influencing factors on the accuracy of the formed parameters during processing is one of the effective sources of increasing the accuracy of processing [14-18].

The aim of the work is to increases the accuracy and productivity of processing conical surfaces and threads of couplings, and thereby their operational indicators.
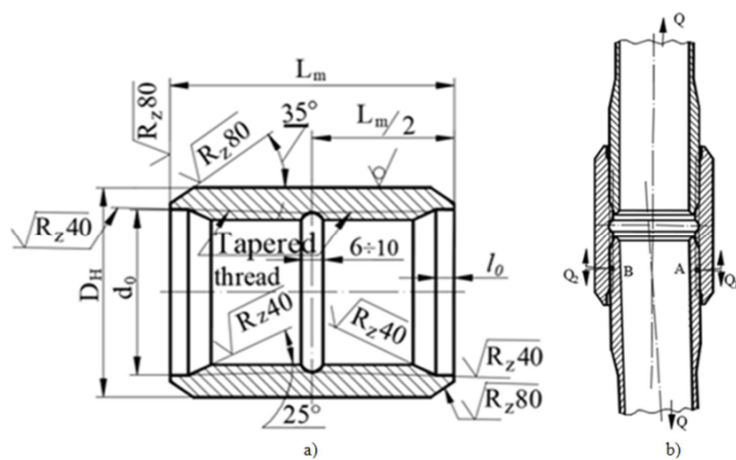

Figure 1. Coupling design (a) and diagram of its working position (b)

\section{Statement of the Problem and Direction of Its Implementation}

To achieve this goal, multivariate technologies have been developed for processing couplings and both tapered threads with a single installation of the coupling and for their implementation means.

Processing the internal smooth surfaces and faces of the couplings from one installation eliminates the auxiliary time for the second installation (or position) of the workpiece and for other components, associated with this, time (for example, for controlling the machine, etc.), reduces the piece time processing: Improving the processing efficiency (IPE) is achieved in a direct way-controlled the technological relationships. When machining threaded surfaces according to the proposed schemes, simultaneous - parallel surfaces machining is carried out, the machine time for threading is almost halved, IPE is achieved in the direct way - by reducing the piece time for processing, controlled the technological relationships [12, 19, 20].

As noted above, tapered surfaces and threads are machined on modern machines when the tool moves along two axes ( $\mathrm{X}$ and $\mathrm{Y})$. Analyzing the formation of the accuracy of the parameters (pitch, taper, half of the profile angle, etc.) of the tapered thread, it was found that reducing the number of factors leading to deviations of the tool radial position to zero will significantly increase the accuracy of thread cutting [19]. In order to achieve higher thread accuracy and increase the manufacturing productivity of couplings, parallel processing of tapered surfaces is used, and cutting of tapered threads and surfaces is carried out without using a radial feed drive of the machine.

For machining threaded is provided special machine tool. The feed for machining tapered threads and smooth tapered surfaces is carried out only along the forming surface. The longitudinal guide of the machine on a horizontal surface is not parallel to the axis of the spindle, as is accepted in practice, but tilted at an angle $(\gamma)$ equal to the angle of inclination of the tapered thread and surfaces $(\varphi) ;(\gamma=\varphi)$. (Figure 1 and 3) [19]. This eliminates the need for radial movement of the tool when forming surfaces. In this case, there is no need to radially move the tool during the formation of tapered threads and surfaces, and only axial movement of the tool with an inclination angle equal to $(\gamma)$ is sufficient for their formation.

When forming tapered threads and surfaces, it is sufficient to carry out only longitudinal movement of the tool along the guides of the machine, at an angle of inclination $\varphi$, relative to the axis of the spindle. At the same time, the transverse guides of the machine are fulfilled perpendicular to the axis of the spindle on a horizontal plane (for machining the face surfaces of the coupling, etc.). This also simplifies the process of setting up a technological system for processing, eliminating the relevance of linking axial and radial dimensions during setup.

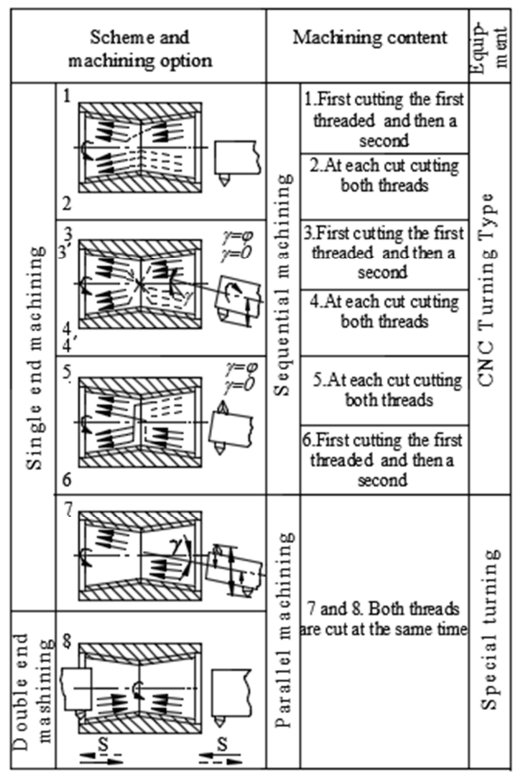

Figure 2. Diagrams of cutting different directional threads from one installation. 
There is the possibility of providing higher precision settings and positioning of the tool when cutting threads on the coupling. Improving the technology for processing tapered threads, including other surfaces of parts of the typecoupling, is carried out in two directions:

a) The accuracy of coaxiality of the tapered threads of the coupling is increased, the bearing capacity of the threaded joints of the couplings is increased;

b) Increases the manufacturing performance of couplings, reduces their technological cost.

We have developed various options for cutting different directional threaded surfaces (including the processing of the accompanying surfaces) of the coupling from one installation (Figure 2).

Improving the processing efficiency of tapered threads and other smooth surfaces of the part-coupling is achieved in two directions:

i. processing of all internal surfaces and threads from the same end

ii. processing of the part from two sides, with two calipers located on opposite sides of the spindle stock (headstock) assembly.

\section{Advanced Technology for Machining the Inner Surfaces of Couplings}

To process the inner surfaces of the couplings, the following, approximate processing sequence is proposed:

i. facing, chamfering;

ii. rough boring of internal smooth surfaces along the contour (sequential or parallel processing);

iii. finish boring of internal smooth surfaces along the contour (sequential or parallel processing);

iv. facing the second end and chamfering (if necessary);

$\mathrm{v}$. boring of the intermediate groove between the tapered threads (if its processing is not combined with the boring of smooth internal surfaces);

vi. sequential or parallel cutting of internal threads.

\subsection{One Side Parallel Processing}

Parallel processing of different directional coaxial taper threads on the couplings from one end is carried out according to scheme 7 (Figure 2). The essence of the method is that when moving the boring bar along the forming cone, the tools installed on it enter the work at the same time and each of them cuts one threaded surface (Figure 3). A characteristic feature of the processing of tapered threads on the proposed machine, with two threaded cutters, is that after setting the appropriate feed rate $\mathrm{S}=>\mathrm{P}$, with cutter $a$ cuts thread $A$ and cutter $b$ cuts thread $B$ at the same time $[19,20]$.

To implement the method, it is necessary to create at each working pass such a distance between the tools that would provide the necessary cutting depths for each tool.

Unilateral parallel processing can be implemented on existing (with $\gamma=0$ ) and special (with $\gamma=\varphi$ ) machines.
Radial approach and retraction of tools can be carried out in two ways:

i. simultaneous movement of both tools relative to the axis of the boring bar;

ii. the radial movement of one of the tools is doubled (relative to the axis of the boring bar), and the movement of the second cutter together with the boring bar is provided from the radial feed drive of the machine.

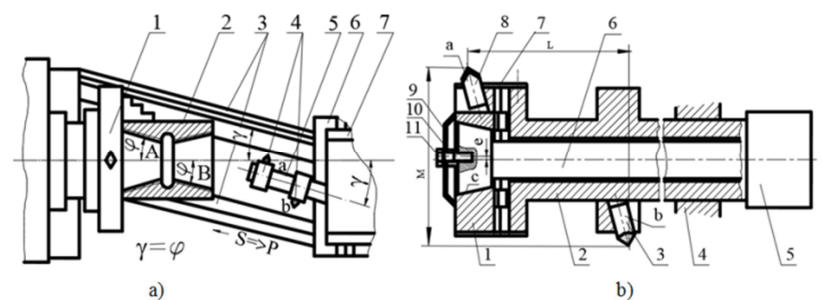

Figure 3. Thread cutting patterns on a special machine (a) and boring bar designs for its implementation (b): 1. Cutter holder, 2. Housing, 3 and 8 . Cutters, 4. Machine tool holder, 5. Hydraulic system mechanism, 6. Pulling, 7. Protective casing, 9. Elastic clamp-casing.

The latter method is simpler and more efficient. A boring bar design has been developed (Figure 3, b), which allows one of the cutting tools to be moved in the radial direction relative to the boring bar axis [20]. With the help of a hydraulic (or pneumatic) drive 5 , is turn the pulling 6 , and thereby the tool holder 1 is turn by the required angle, which determines the radial movement of the cutting tool 8 to the desired cutting depth, due to the eccentricity of the auxiliary base of pulling. The tool holder position of is being fixed. Being Implemented second work pass is, etc.

To ensure the effectiveness of the parallel processing method for different directional tapered threads, the following conditions must be observed:

i. a condition for ensuring parallel processing. The distance between the tools in the axial direction $L$ (Figure 3, b);

ii. condition for the preservation of the thread during removal of the boring bar. The largest permissible radial distance between the tools during the removal of the boring bar is determined from the dimensional ties formed by the threads, taking into account the elastic movement of the elements;

iii. the condition for ensuring the required depth of cut, distance $M$;

iv. the condition of operability of the design, of the device is the value of the eccentricity e of the auxiliary base of the pulling.

When the method of cutting coaxial threads described above is applied the IPE of the coupling is carried out both in the direct way - by reducing piece time (being controlled the technological relationships), and indirectly increasing operational performance due to increased accuracy of coaxialitet for different directional tapered threads (being controlled the technological and operational relationships). 


\subsection{Bilateral Parallel Processing}

Parallel processing on two sides of the different directional tapered threads (and other surfaces) of parts of the couplingtype is carried out according to scheme 8 (Figure 2). Couplings have small lengths. Therefore, the processing of these threads on both sides of the coupling on existing machines have relatively long spindle units is not possible. To process the coupling on both sides and thereby IPE, it is necessary to create machines with shortened spindle units, which allow for the installation of the workpiece and its efficient processing. The design of a similar spindle unit has been developed [21]. The guides of these machines can also be located at an angle $\gamma=\varphi$ relative to the axis of the spindle, and also be parallel to it $(\gamma=0)$, on a horizontal plane.

\subsection{One-side Sequential Thread Processing}

Thread processing is carried out in two versions:

i. First, the first threaded surface is cut, and then the second (Figure 3: 1, 3, 5, 7);

ii. on each working pass of the tool, both threads are cut (Figure 3: 2, 4, 6).

Sequential processing of conical surfaces on special machines (with $\gamma=\varphi$ ) can be carried out with two tools according to schemes 5, 6 and 7 and one tool according to schemes 1, 2, 3, and 4 (Figure 3). In this case, the cutting depths at the beginning and retraction of the tool at the end of each working pass can be carried out:

i. with cross feed, from the drive of the cross carriage of the machine;

ii. with the boring bar, the design of which is equipped with an eccentric device for supplying and removing the tool.

The method of threading with one cutter is as follows (for example, Figure 3: 3): the rotation of the workpiece 2 is reported, fixed in a three-jaw chuck 1 . The threading tool, set to the required size, receives movement along the guides 7 , and first cuts one thread surface $A$, completely, and then rotates together with the boring bar 1 by $180^{\circ}$ around its axis, and without stopping the movement, it cuts another threaded surface $B$ on the workpiece 3 .

i. with transverse feed, from the drive of the transverse support of the machine;

ii. with a design of a boring bcar equipped with an eccentric device for supplying and withdrawing a tool.

The method of threading with one cutter is as follows (for example, Figure 3:3): is reported rotation of the workpiece 2, fixed in a three-jaw chuck 1 . The threading tool set to the required size, receives movement along the guides 7 , and first cuts one thread surface A completely and then rotates together with the boring bar 10 by $180^{\circ}$ around its axis and without stopping the movement, it cuts another threaded surface B on the workpiece 3 .

Cutting on each working pass of the tool, both threads (Figure 3: 2, 4, 6) are carried out as follows: after cutting the first thread, during the first pass, the cutter holder 8 turn $180^{\circ}$ around its axis, and continues its movement by cutting the second threaded surface. The turn of the cutter is carried out when it is in groove between the threaded of the coupling. Then, the tool adjusts to the cutting depth for the second working pass, and in the same way cuts both threads in the second pass, etc.

\section{Production Tests}

To test the cutting of different directional tapered threads of coupling-type parts, sequential processing from one end of thread machining with two tools was selected, to ensure tool inlet and outlet radial is, used the radial feed drive of the machine. The object of research was adopted - Coupling 7PD.001 (material, Steel 45) of a hydraulic packer.

The experiments - the industrial production of the coupling in the production environment were carried out at the Baku oilfield engineering plant, on a model 16420Ф3РМ139 turning and milling machine. The installation of the workpiece is carried out on the external, machined surfaces, with axial basing by the face of the workpiece.

The machining of the internal smooth surfaces of the coupling, including the threaded ones and the faces are carried out according to the processing route presented in above.

The processing of different directional smooth and threaded surfaces was carried out in two variants, based on the processing of both surfaces at the same and in different tool passes (Figure 2: 5 and 4).

When processing surfaces, the corresponding modes, used at the factory were adopted.

The interferences of the threads, the coaxialitet of the different directional tapered threads and the surface roughness were monitored and measured.

Sequential threading in one pass (Figure 2: 5). Thread cutting is carried out by two tools mounted on a boring bar across $180^{\circ}$.

Threads were cut on 50 samples with one adjustment of the technological system (TS). The surface roughness of the cut thread corresponded to the requirements of GOST 633-80 and did not exceed $40 \mu \mathrm{m}(\mathrm{Rz}<40 \mu \mathrm{m})$. The coaxialitet deviation of the threaded threads in the plane of the end face of the coupling was up to $24 \mu \mathrm{m}$. This constitutes approximately a $1 / 3$ part of the entire tolerance provided by GOST.

The range of the interference of cut external (close to the caliper) tapered threads was $0.1 \div 3.6 \mathrm{~mm}$, internal $0.2 \div 4.7$ $\mathrm{mm}$. According to GOST 633-80, for threading tubing $\varnothing 89$, the interferences should be equal to 1 coil of thread, with permissible deviations of \pm 1 coil of thread, i.e. $0 \div 6.35 \mathrm{~mm}$ (pitch, $\mathrm{P}=3.175 \mathrm{~mm}$ ).

The accuracy of the external tapered thread was higher than the accuracy of the internal thread. When cutting both threads, the same boring head is used. Its rigidity was approximately the same in both cases. However, when cutting the external and internal threads, the directions of the components of the cutting forces $\mathrm{P}_{\mathrm{z}}$ and $\mathrm{P}_{\mathrm{y}}$ are opposite $[6,7$, $15,22]$. 
When cutting two different directional threads from one workpiece installation from one end of the coupling with two tools in one pass, the required processing quality is achieved in general, with increased accuracy in the coaxialitet of the threads.

Sequential threadings in different passages (Figure 2). Thread cutting was carried out by a different tools according to scheme 6. Threads were cut on 35 samples with one adjustment of the TS.

To compare the cutting processes of different directional threads of the coupling with the existing cutting processes on both sides, were checked the interferences and coaxialitet of the threads on 30 samples (60 tapered threads), cut at the Azerbaijan Pipe Rolling Plant (during serial production of couplings for tubing $\varnothing 89$, The interferences of tapered threads varied in the range $\Delta \mathrm{H}=0.3-5.42 \mathrm{~mm}$; the deviation from the coaxialitet of the threads in the face plane was up to $0.82 \mathrm{~mm}$.

Thus, the advantages of cutting processes of multidirectional threads (as well as machining of internal surfaces and ends) from one end of the coupling, both from the point of view of increasing the accuracy of the relative positions of the threads and the point of view of reducing piece time, have been identified.

Verification experiments were carried out in laboratory conditions (in the laboratory of Azerbaijan Technical University), on the SL-10 machine manufactured by HAAS. A limited number of $(3+3)$ tapered threads were cut, simulating the design of the pipe threads of the coupling, and similar results were obtained.

\section{Conclusions}

1. Increasing the coaxialitet accuracy of the tapered threads of the coupling and parallel processing of their internal surfaces in one installation and position make it possible to increase the productivity and accuracy of the manufacture of couplings.

2. For increase the coaxialitet of the different directional conical threads and the accuracy of the radial dimensions of the coupling it is proposed they machining on a special machine. Guides of these machines are not parallel to the spindle axis, as is customary. They located obliquely relative to spindle axis and makes up some angle, with it equal to the angle of inclination of the forming conical thread.

3. A multivariate technological process has been developed for cutting different directional tapered threads in parallel and in one installation, and the design of the machine and tooling has been proposed and justified for the implementation of the developed technologies. Wherein, IPE is achieved both directly and indirectly.

4. It has been established that when cutting different directional tapered threads from one workpiece installation, from one end of the coupling with two tools in one pass, the required processing quality is ensured as a whole, and is improved accuracy of coaxialitet in threads and productivity.

\section{References}

[1] Aizuppe E. A., Polyachek D. N. Oil grade pipes. Volume 1 Drill pipes: Samara: LLC As Gard Publishing House, 2012, 284 p. ISBN 978-5-4259-0172-9.

[2] QOST 633-80. Tubing pipes and couplings for them. Specifications. M: Standartinform, 2010. -34 p.

[3] Birger I. A., Iosilevich G. B. Threaded and flange connections. M.: Mechanical Engineering, 1990. - 388 p. K. Elissa, "Title of paper if known," unpublished.

[4] Yakushev A. I., Mustaev R. Kh., Mavlyutov R. R. Improving the strength and reliability of threaded joints M.: Mechanical Engineering, 1979. - $215 \mathrm{p}$.

[5] A New Approach for the Production of Blades by Hybrid Processes By: Calleja A., Fernández A., Rodriguez A, L. N. López de Lacalle and Lamikiz A. Nontraditional Machining Processes Research Advances. J. Paulo Davim Editor. Springer-Verlag London 2013, p. 205-230.

[6] Handbook of the technologist of the machine builder, Ed By: Dalsky A. M., Kosilova A. G., Meshcheryakova R. K. etc.: Mechanical Engineering, 2003. V. 1. 912 p. V. 2. 944 p.

[7] Materials and Processes in Manufacturing By: Paul DeGarmo E, Black J. T., Ronald A. Kohser. Published: 20111130 p.

[8] Quality in the machining: characteristics and techniques to obtain good results By: Lauro C. H., Brandão L. C., Ribeiro Filho S. M. and J. Paulo Davim Manufacturing Engineering: new research, Chapter 5 (51-75), in Davim, J. P (Ed.), Nova Publishers, New York, 2015, ISBN: 978-1-63463-378-9.

[9] Advanced optimal tolerance design of mechanical assemblies with interrelated dimension chains and process precision limits By: Singh, PK; Jain, SC; Jain, PK Computers in Industry. Volume: 56 Issue: 2 Pages: 179-194 Published: 2005.

[10] Interrelated Dimensional Chains in Predicting Accuracy of Turbine Wheel Assembly Parameters By: Yanyukina, M. V.; Bolotov, M. A.; Ruzanov, N. V. 11th International Conference on Mechanical Engineering, Automation and Control Systems (MEACS) Book Series: IOP Conference Series-Materials Science and Engineering Volume: 327 Russia Published: 2018.

[11] Investigation of mechanical error in four-bar mechanism under the effects of link tolerance By: Jawale, H. P.; Jaiswal, Ankur Journal of the Brazilian Society of Mechanical Sciences and Engineering Volume: 40 Issue: 8 Article Number: UNSP 383 Published: 2018.

[12] Rasulov N. M. Management of technological dimensional relationships and the efficiency of processing machine parts.

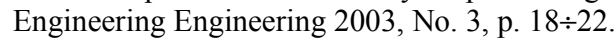

[13] Rasulov N. M. Make quality control under its production. Vestnik Mashinostroeniya, 2013, no. 2, pp. 83-86. (in Russian).

[14] Backlash Error Measurement and Compensation on the Vertical Machining Center By: Huanlao Liu, Xiaoning Xue, Guangyu Tan. Engineering, Vol. 2 No. 6, 2010, pp. 403-407. 
[15] CNC-Handbuch 2009/2010. Carl Hanser By: Hans B. Kief, Helmut A. Roschiwal. Verlag, Munchen. 2009. 551 p.

[16] Derivation of machine tool error models and error compensation procedure for three axes vertical machining center using rigid body kinematics By: Okafor A. C., Ertekin Y. M. International Journal of Machine Tools \& Manufacture, 40 (2000) 1120-1221.

[17] Relation between kinematic straightness errors and angular errors of machine tool By: Majda P. Advances in Manufacturing Science and Technology, vol. 36, no. 1, 2012, pp. $47-53$.

[18] Rasulov N. M., Nadirov U. M. Evaluation of parts production quality in instrument-making. Scientific and Technical Journal of Information Technologies, Mechanics and Optics, 2019, vol. 19 , no. 4, pp. 747-755 (in Russian). doi: 10.17586/2226-14942019-19-4-747-755.
[19] Rasulov N. M. A method of processing two different directional tapered threads. Invention of the USSR, No. 1662776. Bull. Inventions, 1991, No. 26.

[20] Rasulov N. M. Device for processing different directional conical threads. Invention of the USSR, No. 1303303. Bull. inventions. 1987, No. 14.

[21] Rasulov N. M., Gafarov S. A. Clamping device. Invention of the USSR. No. 1220872. Bull. Inventions, 1986, No. 12.

[22] Experimental study of cutting force on a cutting tool during machining using inverse problem analysis By: Patil, Ratan A.; Gombi, Shrinivas L. Journal of the Brazilian Society of Mechanical Sciences and Engineering Volume: 40 Issue: 10. Article Number: UNSP 494. Published: 2018. 